\title{
Eutectic: Phase Change Material for Food Storage
}

\author{
Chaitrali P. Salgaonkar+*, Rujuta S. Kulkarni†, Dheeraj D. Kulkarni ${ }^{\ddagger}$ \\ †Mechanical, Savitribai Phule Pune University, Kothrud, Pune, Maharashtra, India \\ ‡Mechanical, University of Mumbai, Koparkhairane, Maharashtra, India \\ Accepted 02 March 2016, Available online 15 March 2016, Special Issue-4 (March 2016)
}

\begin{abstract}
Eutectic plates are widely used in refrigerated vehicles to keep the temperature of the container in desired range, eliminating or including the refrigeration unit. Eutectic is a phase change material which remains unaffected by cyclic heating and cooling. Eutectic plates consists a mixture of two or more compounds which has low melting point than that of each individual compound. Eutectic is a solution which has phase change temperature below $0^{\circ} \mathrm{C}\left(32^{\circ} \mathrm{F}\right)$. Eutectic plates consume energy for freezing during night and during day period it operates to keep the storage container at a constant prearranged temperature by absorbing and dissipating large amount of thermal energy, without consuming energy. The eutectic material is stored in stainless steel, aluminium and high density polyethylene pipes. Using eutectic plates on refrigerated boards eliminate the use of bulky refrigeration unit which reduces chances of failure of the system components due to vibrations during transportation and make the system simple. Also the $\mathrm{CO}_{2}$ emission contracts to a greater extend.
\end{abstract}

Keywords: Eutectic, Phase Change Material, Thermal Energy, Transportation.

\section{Introduction}

Having large latent heat of fusion phase change materials are widely being used in thermal industries like food industry, process industry and transportation. 'Eutectic System' is used in refrigeration system which absorbs and liberates heat at constant imparted temperature. Eutectic materials have large latent heat of fusion, this property of the material makes it popular to use in refrigeration system. Eutectic is mixture of two or compounds in proportion having freezing point less than that of the individual compound. The installation of eutectic plates is done in food storage containers of vans or can be used as a backup for on ground refrigerators. Eutectic plates are mounted on the walls, doors and ceiling of the containers. Eutectic plates can be used with or without assistance of vapour compression refrigeration system. Eutectic plates have proved to be a boon for short distance food transportation as this system can work for nine to twelve hours with one time freezing. Frequent opening of doors lead to addition of heat load which affects the performance of eutectic plates. Once charged the operation of eutectic plate is silent and it is reliable source of cooling for a specific time span.

\section{Eutectic solvents}

In recent common organic media having needs inherent toxicity and high volatility are being replaced by green technology. Deep Eutectic Solvents (DES) are formed by mixing two compounds in a proportion which gives a substance having significant low melting point. Choline chloride $(\mathrm{ChCl})$, Carboxylic acid and other hydrogen-bond donors, such as urea, citric acid succinic acid and glycerol are oftenly used. DES are cheaper to produce, both due to less complexity of synthesis and expenses of the required raw material. Natural deep eutectic solvents (NADES) are recently found with base material like organic acid, amino acids and sugars. DES are blend of Lewis and Bronsted acids and bases containing anions and cations . Density of all NADES is around $20 \%$ higher than that of water.

NADES prepared in Table 1 . are the amount of material prepared to attain the molar ratios shown in the table dissolved in $\mathrm{H}_{2} \mathrm{O}$. The two solutions are mixed and exposed to vacuum at $50^{\circ} \mathrm{C}$ in a rotary evaporator to remove water.

Table 1: NADES preparation and water content

\begin{tabular}{|c|c|c|c|c|}
\hline Component 1 & Component 2 & Ratio & $\begin{array}{c}\text { Density/ } \\
\text { g.mL }\end{array}$ & $\begin{array}{c}\text { Water } \\
\text { Content }(\% \\
\text { Wt })\end{array}$ \\
\hline $\begin{array}{c}\text { Choline } \\
\text { chloride }\end{array}$ & Citric acid & $1: 1$ & 1.3 & 0.2 \\
\hline $\begin{array}{c}\text { Choline } \\
\text { chloride }\end{array}$ & D-(+)-sucrose & $4: 01$ & 1.22 & 0.2 \\
\hline $\begin{array}{c}\text { Choline } \\
\text { chloride }\end{array}$ & D-(+)-sucrose & $1: 01$ & 1.35 & 0.2 \\
\hline $\begin{array}{c}\text { Choline } \\
\text { chloride }\end{array}$ & $\begin{array}{c}\text { L-(+)-tartaric } \\
\text { acid }\end{array}$ & $2: 01$ & 1.26 & 1.9 \\
\hline $\begin{array}{c}\text { Choline } \\
\text { chloride }\end{array}$ & D-(+)-glucose & $1: 01$ & 1.27 & 5.5 \\
\hline
\end{tabular}




\begin{tabular}{|c|c|c|c|c|}
\hline $\begin{array}{c}\text { Choline } \\
\text { chloride }\end{array}$ & D-(+)-xylose & $2: 01$ & 1.23 & 3.8 \\
\hline $\begin{array}{c}\text { Choline } \\
\text { chloride }\end{array}$ & D-(+)-xylose & $3: 01$ & 1.22 & 0.2 \\
\hline Citric acid & D-(+)-sucrose & $1: 01$ & 1.43 & 1.2 \\
\hline Citric acid & D-(+)-glucose & $1: 01$ & 1.45 & 0.5 \\
\hline D-(+)-glucose & $\begin{array}{c}\text { L-(+)-tartaric } \\
\text { acid }\end{array}$ & $1: 01$ & 1.46 & 0.4 \\
\hline
\end{tabular}

\section{Construction}

\section{Encapsulation}

There are two ways in which encapsulation is done macro and micro encapsulation. In microencapsulation particles from 1-1000 $\mu \mathrm{m}$ diameter are closely packed and then arranged in continuous matrix. Heat transfer is mainly due to conduction because of the close arrangement and rigidity of the matrix. Due to this reason heat transfer rate is found to be less and subcooling is higher. Nano-encapsulation is a technique widely spreading due to its advantages over micro capsulation. Particles of diameters around 10-100 $\mu \mathrm{m}$ are inserted in nano-capsulation [6]. To avert breaking of container due to volume expansion during freezing, considerable allowance is provided between container and solution.

\section{Material}

a. Stainless steel

b. Aluminium

c. High density poly ethylene

d. Natural fibre

\section{Types of Eutectic Plates}

a. Flat Container

Flat container is constructed with the help of steel, aluminium and HDPE. HDPE containers are formed by blow moulding HDPE and can be used in positive and negative temperatures. Steel flat plate containers are covered by thin layer of zinc for preventing it from corrosion. Aluminium plates provide better heat transfer rate and show better performance.

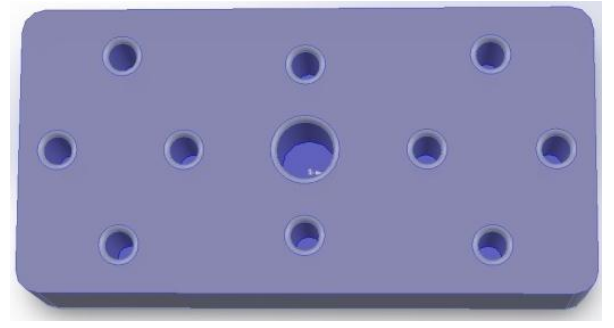

Fig.1 Flat container

\section{b. Tube Container}

The operation of flat container is same as that of flat container. Tube containers are the completely sealed tubes (may be round, square or of any cross section) filled with eutectic material. Tube containers can be staked in square or circular pattern reducing voids. Hence, energy transfer obtained is more uniform in tube containers.

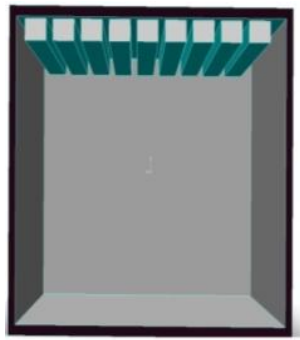

Fig.2 Tube container

\section{c. Board Container}

The encapsulation material used in this type is a natural fibre like wood. This container is infused with organic PCM solutions. Once the infusion process is done, natural fibre board is compressed to a solid board. The compression along with high pressure and temperature is applied during a pressing process. The optimum PCM coverage in the board is achieved by compression, this leads to improvement in thermal storage capacity.

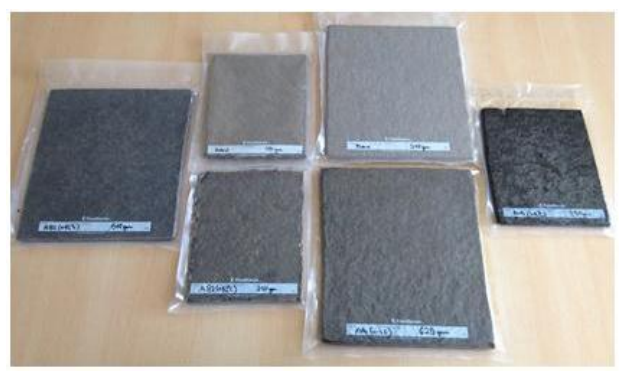

Fig.3 Board container

d. Transport eutectic plate

Transport eutectic plate is metallic or flexible plate which is used to keep the storage box temperature at desired level. These are filled with gel or liquid and can last long for 5-10 hours. These packs are used for short trips and keep food fresh longer.

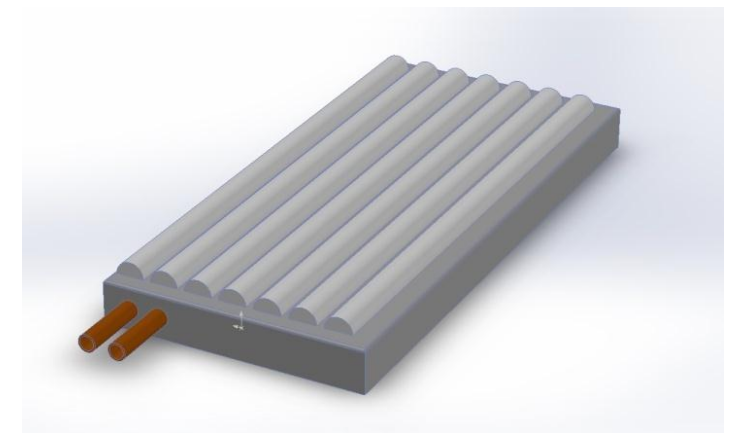

Fig.4 Transport eutectic plate 
e. Eutectic pouches

Eutectic pouches are used to keep the cold chain preserved in all fields like (pharmaceutical) medical products transportation, autonomous cold, samples shipping, specialist hauliers, food processing industries and medical analysis laboratories. The eutectic packs are frozen to a temperature less than $5{ }^{0} \mathrm{C}$ lower than its eutectic solidification point. It maintains the heat sensitive product within the desired temperature range for a specific period of time, depending upon the number of packs used. It has strong coldness restitution. It is non toxic product.Putting them into a brine solution upto a very low temperature and then in morning are mounted in the vehicle to be travelled. The other method for freezing the eutectic plates is to charge the eutectic system with electric supply system (Mains power), this can be done in two ways on board charging and off board charging. A huge amount of food is transported with refrigerated vehicles nowadays. Eutectics operate with or without mechanical refrigeration as a back-up cooling option for safe and reliable operating of the system.

\section{Application}

- $\quad$ Fresh produced transport

- Medicine storage

- Vaccine transport

- Ice-cream vending

- Beverage vending

- Chilled goods transport

- Frozen food transport

- Marine refrigeration

- Truck refrigeration

- Transport container

- Ice packs

\section{Advantages}

- Eutectics have large hold over of period due to latent heat carrying capacity and significantly eutectics phase change.

- As evaporation of refrigerant takes place in a saturated environment, power consumption is very less.

- Large hold over period during power cut off.

- Easy to install.

- Suitable to every climatic condition.

- Easy to handle.

- Carbon foot prints are reduce significantly as diesel consumption is reduced.

\section{Disadvantages}

- Hold over period is less i.e. only of 9 to 12 hours.

- Heat load addition takes place in case of frequent door openings.

\section{Conclusion}

Eutectic plate system is on or off vehicle refrigeration unit proposed for refrigeration and cold chain. This system uses latent heat of eutectic solvents which are phase change material to liberate and absorb heat from the container. This system reduces energy cost of refrigeration unit by $86.4 \%$ as reduction in usage of diesel and electricity. It also performs noiseless operation. Eutectic solvents are not much exposed. Hence, research is going on to form new eutectic solvents having higher capacity and hold over period.

\section{References}

L. Vaitkus, V. Dagilis,(2014), Refrigeration charge reduction in low temperature transport refrigerator with the eutectic plate evaporator, International Journal of Refrigeration, 4657.

R. Craverio, I. Aroso, V. Flammia, T. Carvalho, M. T. Viciosa, M. Dionisio, S. Brarreiros, R.L. Reis, A.R.C. Duarte, A. Paiva,(2016), Properties and thermal behaviour of natural deep eutectic solvents, Journal of Molecular Liquids, 534540

W. Lu, S.A. Tassou, (2013), Characterization and experimental investigation of phase change materials for chilled food refrigerated cabinet applications, Applied Energy 112, 1376-138

S.A. Tassou, G. De-Lille, Y.T. Ge, (2009), Food transport refrigeration - Approaches to reduce energy consumption and environmental impacts of road transport, Applied Thermal Engineering 29,1467-147

Mahmood Mastani Joybari, Fariborz Haghighat, Paul Sra, (2015), Heat and cold storage using phase change materials in domestic refrigeration systems: The State of The art Review, Energy and building

R.K. Sharma, P. Ganesan, V.V. Tyagi, H.S.C. Metselaar, S.C. Sandaran, (2015), Developments in organic solid-liquid phase change materials and their applications in thermal energy storage, Energy Conversion and Management 95, 193-22

Emma, L. Smith, Andrew P. Abbott, Karl S. Ryder,(2014), Deep eutectic solvents and their applications, ACS Publication. 